\title{
A dynamic approach for evaluating coarse scale satellite soil moisture products
}

\author{
A. Loew ${ }^{1}$ and F. Schlenz ${ }^{2}$ \\ ${ }^{1}$ Max-Planck-Institute for Meteorology, KlimaCampus, Hamburg, Germany \\ ${ }^{2}$ Department of Geography, University of Munich, Munich, Germany
}

Received: 15 August 2010 - Published in Hydrol. Earth Syst. Sci. Discuss.: 24 September 2010

Revised: 10 December 2010 - Accepted: 22 December 2010 - Published: 11 January 2011

\begin{abstract}
Validating coarse scale remote sensing soil moisture products requires a comparison of gridded data to pointlike ground measurements. The necessary aggregation of in situ measurements to the footprint scale of a satellite sensor $\left(>100 \mathrm{~km}^{2}\right)$ introduces uncertainties in the validation of the satellite soil moisture product. Observed differences between the satellite product and in situ data are therefore partly attributable to these aggregation uncertainties. The present paper investigates different approaches to disentangle the error of the satellite product from the uncertainties associated to the up-scaling of the reference data. A novel approach is proposed, which allows for the quantification of the remote sensing soil moisture error using a temporally adaptive technique. It is shown that the point-to-area sampling error can be estimated within $0.0084\left[\mathrm{~m}^{3} / \mathrm{m}^{3}\right]$.
\end{abstract}

\section{Introduction}

There is ample evidence that atmospheric and climate processes are significantly conditioned by the availability of water in the soils (Fast and McCorcle, 1991; Clark and Arritt, 1995; Koster et al., 2004). Soil moisture is an essential climate variable that has importance for the interactions between the land surface and atmosphere. It is thus an essential variable in climate research and numerical weather forecast as well as land surface hydrology. Satellite remote sensing has been demonstrated to provide useful information on soil moisture dynamics at various temporal and spatial scales (Zribi and Dechambre, 2002; Bindlish and Barros, 2000; Wigneron et al., 2004, 2003; Loew et al., 2006; Schwank et al., 2005; Owe et al., 2008). Two dedicated

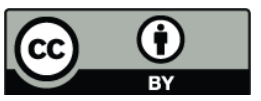

Correspondence to: A. Loew (alexander.loew@zmaw.de) satellite soil moisture missions have been designed to provide global information on soil moisture dynamics. The European Soil Moisture and Ocean Salinity mission (SMOS) (Kerr et al., 2001) was launched in November 2009 and is the first dedicated soil moisture mission ever built. The NASA Soil Moisture Active Passive mission (SMAP) (Entekhabi et al., 2010) is planned to be launched in 2014. These satellite missions will provide information on soil moisture dynamics at global scale and with medium to coarse spatial resolutions $\left(10^{2} \ldots 10^{3} \mathrm{~km}^{2}\right)$. A critical aspect of the missions success is the validation of their soil moisture products to verify if they meet pre-defined accuracy requirements. This validation exercise is complicated by the scale mismatch between the satellite footprint and local in situ measurements of soil moisture which serve as a reference.

A large number of continuous soil moisture measurements would be needed to determine the soil moisture dynamics at the footprint scale (Yoo, 2002; Brocca et al., 2007; Famiglietti et al., 2008) with an accuracy better than $0.04\left[\mathrm{~m}^{3} / \mathrm{m}^{3}\right]$, which is the typical accuracy requirement for satellite soil moisture missions (Kerr et al., 2001; Walker and Houser, 2004).

Typically, characteristic soil moisture patterns develop in a landscape that remain stable at different temporal and spatial scales (Vachaud et al., 1985; Vinnikov et al., 1996). The analysis of temporally stable soil moisture patterns has been used for the development of concepts for the upscaling of local soil moisture measurements to larger scales that could be used for the validation of satellite soil moisture products (Cosh et al., 2004, 2006). A different concept for the evaluation of the error of satellite soil moisture products has been investigated by Miralles et al. (2010). They applied the so called triple collocation (TC) method to quantify the uncertainty of soil moisture data sets using data from three independent sources. Triple collocation analysis has been first used by Scipal et al. (2009) to quantify the error

Published by Copernicus Publications on behalf of the European Geosciences Union. 
characteristics of two different remote sensing soil moisture data set and soil moisture derived from a land surface model. Miralles et al. (2010) then adopted the approach to assess the soil moisture ground validation problem. They compared a passive microwave soil moisture product with soil moisture from a land surface model and sparse ground based observations. They could show that the TC technique provides a useful alternative to address the satellite soil moisture validation problem and that it is possible to quantify the soil moisture error with an accuracy of $0.0064\left[\mathrm{~m}^{3} / \mathrm{m}^{3}\right]$ for their test site.

The objective of the present paper is to investigate the potential synergies of combining in situ soil moisture information with distributed land surface modeling for the validation of satellite products. The paper investigates the potential of using temporally stable soil moisture patterns as well as the TC method for the validation of remote sensing soil moisture products. A temporally dynamic validation approach is proposed which applies the TC method for monthly temporal slices and provides a framework for the quantification of the uncertainties of a satellite based soil moisture product. The novelty of the approach is that it provides uncertainty estimates of soil moisture products at rather short timescales and is able to identify periods where either the satellite measurements or the in situ measurements don't provide reliable information on the large scale soil moisture dynamics.

The method is verified on a core soil moisture validation site situated in Southern Germany using AMSR-E soil moisture products. The used methods and data are first introduced in Sect. 2 and 3. Results from the analysis of the two methods are then presented in Sect. 4 and 5 and results are discussed in Sect. 6.

\section{Methodology}

A key question for the validation of remote sensing soil moisture data products is an appropriate accuracy assessment of the data products. Typically, the root mean square deviation (RMSD) is used to predefine the accuracy requirements of a satellite soil moisture product (?Kerr, 2007). It is defined as

$\operatorname{RMSD}=\sqrt{\left\langle(x-y)^{2}\right\rangle}=\sqrt{\operatorname{var}(x)+\operatorname{bias}(x, y)^{2}}$

whereas $x$ and $y$ correspond to vectors of collocated satellite and in-situ observations respectively. Angled brackets indicate ensemble averaging. The user requirement for global satellite soil moisture products is currently defined with RMSD $\leq 0.04\left[\mathrm{~m}^{3} / \mathrm{m}^{3}\right]$ (Walker and Houser, 2004; Kerr et al., 2001). However as by its definition, the RMSD is very sensitive to a bias between in situ reference data and the satellite product. Even if a product would perfectly reproduce the relative temporal soil moisture dynamics it would show a large RMSD if the estimates or used reference data are biased. Biases in remote sensing soil moisture estimates might result from a variety of sources, like e.g. imperfect characterization of the land surface in the retrieval scheme or variable sensitivity of the observation system to soil moisture dynamics (van de Griend et al., 2003; Loew, 2008).

Regular in situ soil moisture measurements are typically based on a relative small number of samples compared to the footprint scale of a satellite sensor. The monitoring of soil moisture dynamics using a very high number of observations is limited to dedicated campaigns (Famiglietti et al., 2008; Peischl et al., 2009; Jackson et al., 2005, e.g.). Existing regular soil moisture networks like the Oklahoma Mesonet network (www.mesonet.org) (Brock et al., 1995), the REMEDHUS network in Spain (Ceballos et al., 2002), OzNet in Australia (www.oznet.org.au) or the SMOSHYD validation site (Loew et al., 2009a) provide in situ data from only a few stations $N<10$ for an area corresponding to the footprint of dedicated soil moisture missions like SMOS.

Ground based soil moisture measurements are typically only representative for very small volumes in the order of $10^{-4} \mathrm{~m}^{3}$ and thus remain very local (for a comparison of different measurement techniques see Walker et al., 2004). Currently, no global in situ soil moisture monitoring network exists. First efforts to collect reference data of in situ soil moisture was made by Robock et al. (2000). More recently, a research community driven in situ soil moisture network has been initiated to collect and distribute harmonized and quality proofed in situ soil moisture data (http://www.ipf.tuwien.ac.at/insitu/).

As the soil moisture spatial variability in the footprint of a satellite sensor can be large, the mismatch between in situ measurements and the satellite footprint scale results in large uncertainties for the validation of satellite soil moisture products. An appropriate validation approach therefore needs to take into account the inherent uncertainties that are associated with the upscaling of local scale soil moisture measurements to a larger scale. Two different approaches will be introduced in the following two sections and their potential will be investigated in the further analysis of the paper.

\subsection{Temporal stable soil moisture patterns}

The concept of temporal stability was introduced by Vachaud et al. (1985) as a mean to represent large scale soil moisture dynamics using a measurement network of a few sites only. The fundamental assumption of the method is that characteristic soil moisture patterns persist, which can be used to develop time-invariant relationships between local $(\theta)$ and large scale $(\bar{\theta})$ soil moisture dynamics in the spatial domain $R$ with an area $A$ which is given by

$\bar{\theta}=A^{-1} \int_{R} \theta d r \approx \frac{1}{N} \sum_{i=1}^{N} \theta_{i}+\epsilon$

and can be approximated by a discrete number of $N$ measurements. The index $i$ specifies the in situ measurements at point $P$ with coordinates $(x, y)$ and $\epsilon$ is the error of (2) due to the discrete approximation. The number of measurements required to obtain a specific accuracy might vary, depending on 
the heterogeneity of the study area. Brocca et al. (2007) used a statistical approach to infer the number of required samples for different spatial scales and concluded that 15 to 35 measurement sites are needed to estimate $\bar{\theta}$ with an absolute error of $0.02\left[\mathrm{~m}^{3} / \mathrm{m}^{3}\right]$ for a study area with a size of $10^{4} \mathrm{~m}^{2}$. As the variability of soil moisture is also dependent on the soil moisture dynamic itself, the number of required samples might vary as a function of $\bar{\theta}$ (Vereecken et al., 2007). Famiglietti et al. (2008) provide an analysis of a large number of soil moisture measurements from different campaigns and at various scales. They conclude that the number of measurements required to estimate $\bar{\theta}$ with an accuracy better than $0.04\left[\mathrm{~m}^{3} / \mathrm{m}^{3}\right]$ (95\% confidence level) is larger than $N=20$ for a scale of $50 \times 50 \mathrm{~km}^{2}$ with decreasing sample numbers for very dry or wet conditions.

A point $i$ is considered to be temporally stable if its soil moisture dynamics is in good agreement with the spatial average. The relative soil moisture difference at time $j$ is given as

$\delta_{i j}=\frac{\theta_{i j}-\bar{\theta}_{j}}{\bar{\theta}_{j}}$

The expected value of $\bar{\delta}_{i}$ and its standard deviation is then obtained from $M$ times as

$\overline{\delta_{i}}=\frac{1}{M} \sum_{j=1}^{M} \delta_{i j}$

$\sigma\left(\delta_{i}\right)=\sqrt{\frac{1}{M-1} \sum_{j=1}^{M}\left(\delta_{i j}-\bar{\delta}_{i}\right)^{2}}$

A point which is representative for the large scale soil moisture dynamics therefore corresponds to small values of $\left|\bar{\delta}_{i}\right|$ and $\sigma\left(\delta_{i}\right)$. If stable relationships between the local and large scale soil moisture dynamics exist, these can be used for the upscaling of local measurements to the larger scale (Brocca et al., 2010).

Spatially persistent soil moisture patterns have been analyzed using ground measurements (Vachaud et al., 1985; Grayson and Western, 1998; Cosh et al., 2004; MartinezFernnandez and Ceballos, 2005; Teuling et al., 2006), models (Loew and Mauser, 2008) or remote sensing observations (Wagner et al., 2008). Techniques to dissaggregate coarse scale remote sensing observations using prior knowledge of persistent soil moisture fields have been developed (Loew and Mauser, 2008; Wagner et al., 2008).

The temporal stability approach assumes that a specific location can be found where the relationship between local and large scale soil moisture dynamics is time-invariant. It will be evaluated in Sect. 4 if this assumption is applicable for the data used in the present study and contrasted against the triple collocation approach introduced next.

\subsection{Triple collocation method}

The triple collocation (TC) method was originally developed to estimate the errors of sea wind and wave height estimates derived from buoy, model and satellite data (Stoffelen, 1998; Caires and Sterl, 2003). It estimates the uncertainties of observations of a geophysical quantity using time series of three independent data sets.

Scipal et al. (2009) was the first to apply the TC method to quantify uncertainties of surface soil moisture data, using data from two different remote sensing soil moisture products and ERA-40 reanalysis data. The method was then used for validation of remote sensing surface soil moisture observations using sparse in situ networks by Miralles et al. (2010). Their approach was based on the analysis of anomalies of time series of a surface soil moisture product derived from AMSR-E (Jackson et al., 2010). In contrast to this anomaly approach, the method of Scipal et al. (2009) was based on measured time series directly.

The implementation of the TC method in the present study follows the analytical solution provided by Caires and Sterl (2003) and uses measured time series of three soil moisture observations. The method and used notation is briefly introduced in the following.

Let us assume that three temporally collocated time series of $n$ observations $\left(x_{i}, y_{i}, z_{i}, i=1 \ldots n\right)$ of an arbitrary physical quantity $T_{i}, i=1 \ldots n$ exist. Their respective random errors $\left(e_{x}, e_{y}, e_{z}\right)$ are assumed to have zero mean. The true measurements $(X, Y, Z)$ of $T$, corresponding to the observations $\left(x_{i}, y_{i}, z_{i}\right)$ are related to $T$ as

$$
\begin{aligned}
& x=X+e_{x}=\alpha_{0}+\beta_{0} T+e_{x} \\
& y=Y+e_{y}=\alpha_{1}+\beta_{1} T+e_{y} \\
& z=Z+e_{x}=\alpha_{2}+\beta_{2} T+e_{z}
\end{aligned}
$$

where the time subscripts have been dropped for easier notation. Removing the mean from each of the variables and denoting the anomalies as $x^{*}, y^{*}, z^{*}, T^{*}$, their relationship is given by

$$
\begin{aligned}
& x^{*}=\beta_{0} T^{*}+e_{x} \\
& y^{*}=\beta_{1} T^{*}+e_{y} \\
& z^{*}=\beta_{2} T^{*}+e_{z}
\end{aligned}
$$

If we assume that the errors of the data sets are uncorrelated, $\left\langle e_{x} e_{y}\right\rangle=\left\langle e_{x} e_{z}\right\rangle=\left\langle e_{y} e_{z}\right\rangle=0$, and independent of $T$, $\left\langle T e_{x}\right\rangle=\left\langle T e_{y}\right\rangle=\left\langle T e_{z}\right\rangle=0$, we can remove the unknown deterministic variable $T^{*}$ using a simple elimination procedure (see for details, Caires and Sterl, 2003) and obtain

$$
\beta_{1}=\beta_{0}\left\langle y^{*} z^{*}\right\rangle /\left\langle x^{*} z^{*}\right\rangle
$$$$
\beta_{2}=\beta_{0}\left\langle y^{*} z^{*}\right\rangle /\left\langle x^{*} y^{*}\right\rangle
$$

where angled brackets $\langle\cdot\rangle$ denote ensemble averaging. The variances of the observation errors are then obtained as

$$
\begin{aligned}
& \operatorname{var}\left(e_{x}\right)=\left\langle e_{x}^{2}\right\rangle=\left\langle\left(x^{*}\right)^{2}\right\rangle-\left\langle x^{*} y^{*}\right\rangle\left\langle x^{*} z^{*}\right\rangle /\left\langle y^{*} z^{*}\right\rangle \\
& \operatorname{var}\left(e_{y}\right)=\left\langle e_{y}^{2}\right\rangle=\left\langle\left(y^{*}\right)^{2}\right\rangle-\left\langle x^{*} y^{*}\right\rangle\left\langle y^{*} z^{*}\right\rangle /\left\langle x^{*} z^{*}\right\rangle \\
& \operatorname{var}\left(e_{z}\right)=\left\langle e_{z}^{2}\right\rangle=\left\langle\left(z^{*}\right)^{2}\right\rangle-\left\langle x^{*} z^{*}\right\rangle\left\langle y^{*} z^{*}\right\rangle /\left\langle x^{*} y^{*}\right\rangle
\end{aligned}
$$



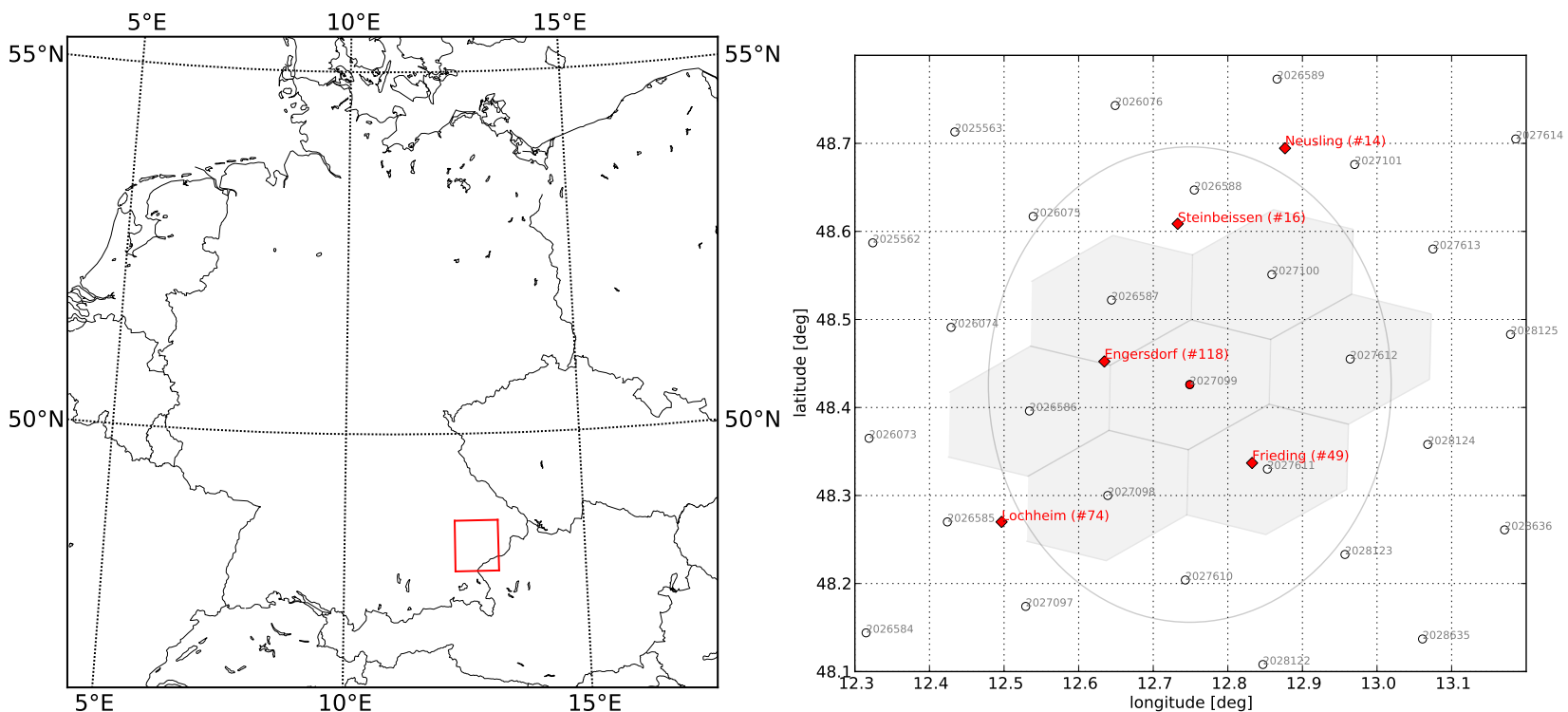

Fig. 1. Location of test site (left) and details of used in situ stations and their mapping to the ISEA grid. The polygons correspond to ISEA grid cells used for the analysis of land surface model simulations. The circle corresponds to the AMSR-E like footprint size.

Finally the coefficients $\alpha_{1}$ and $\alpha_{2}$ are estimated as

$\alpha_{1}=\langle y\rangle-\beta_{1}\left(\langle x\rangle-\alpha_{0}\right)$

$\alpha_{2}=\langle z\rangle-\beta_{2}\left(\langle x\rangle-\alpha_{0}\right)$

Note, that only four of the six coefficients can be derived using $x, y, z$. Defining one observation (e.g. $x$ ) as a reference, $\alpha_{1}, \alpha_{2}, \beta_{1}$ and $\beta_{2}$ can be estimated. Typically it is assumed that the reference is a bias free estimator of the deterministic variable (Scipal et al., 2009; Caires and Sterl, 2003), thus $\alpha_{0}=0$ and $\beta_{0}=1$. However, in a strict sense, this assumption might not be valid. In fact, it will be shown that the ground stations in the present study are not a bias free estimator of the large scale soil moisture content.

Further, modeled soil moisture as well as satellite retrievals have typically biases and exhibit their own characteristics. The data is therefore typically rescaled before using soil moisture observations for e.g. data assimilation purposes. Such a rescaling is crucial, as data assimilation techniques typically rely on the assumption of bias free observations (Reichle et al., 2004; Albergel et al., 2010). In that sense, the estimation of $\alpha$ and $\beta$ parameters corresponds to a similar rescaling of the original data sets. However, the estimation of the errors is independent of such a rescaling, as their value is not dependent on the scaling parameters $\alpha$ and $\beta$ any more, as can be seen from (8) and (9). In situ soil moisture data will be used as the un-biased reference data $(x)$ in the present study.

\section{Study area and data}

Three different soil moisture data sets are used in the present study. These are based on ground observations, land surface model simulations and remote sensing soil moisture estimates. The datasets and their characteristics are described after a brief introduction to the study area.

\subsection{Study area}

The study area is located in the Upper Danube catchment area which is situated in Southern Germany (Fig. 1). A remote sensing soil moisture validation site has been established in a small sub-catchment (Vils), situated in the Northeast of the city of Munich (Loew et al., 2009a). The site is most suitable for validation of coarse resolution microwave remote sensing data as the microwave signal is not affected by open water water bodies or large urban areas which might have a considerable effect on the microwave signal (Loew, 2008).

To perform a cross comparison between the different data sets, these are reprojected to a common, equal area grid. The Icosahedral Snyder Equal Area projection (ISEA4H9) is used as the reference projection (Sahr et al., 2003) which has a grid spacing of $15 \mathrm{~km}$. The same grid is used as a reference grid for the Soil Moisture and Ocean Salinity Mission (SMOS). Each grid node has a unique identifier which will be used in the following to identify ground stations, model grid cells and satellite footprints. 


\subsection{Soil moisture data}

\subsubsection{Soil moisture measurements}

Half-hourly measurements of soil moisture profiles are available since mid of 2007 from five stations in the test site. Soil moisture measurements are made using Time-DomainReflectrometry (TDR) probes at depth of $0.05,0.1,0.2$ and $0.4 \mathrm{~m}$. Surface soil moisture at $0.05 \mathrm{~m}$ is measured by two different probes independently. The stations cover an area of approximately $40 \times 40 \mathrm{~km}^{2}(1)$.

\subsubsection{Land surface model}

The PROMET land surface model is used in the present study to simulate the surface energy and water fluxes (Mauser and Bach, 2009) on an hourly basis. The model consists of a kernel model which is based on five sub-modules (radiation balance, soil model, vegetation model, aerodynamic model, snow model) to simulate the actual water and energy fluxes and a spatial data modeler, which provides and organizes the spatial input data on the field-, micro and macro-scale. Soil moisture dynamic is simulated using a modified version of the Richards equation for flow in unsaturated media (Philip, 1957). The soil water retention model of Brooks and Corey (1964) is used to relate soil moisture content to soil suction head. A detailed description of the model is given by Mauser and Bach (2009). The soil water model has been validated in different test sites using in-situ soil moisture measurements of soil moisture profiles (Pauwels et al., 2008).

PROMET model simulations are made on $1 \mathrm{~km}^{2}$ grid. The meteorological forcing is obtained from a dense network of stations which are collocated with the in situ soil moisture network. Model simulations at $1 \mathrm{~km}^{2}$ scale are made from 1st of November 2007 until end of 2009. The high resolution model simulations are then aggregated to estimate the expected large scale soil moisture dynamics at the footprint scale of a satellite sensor (see Fig. 1).

\subsubsection{Satellite soil moisture}

Remote sensing soil moisture data are obtained from a globally available data set based on the Advance Microwave Scanning Radiometer (AMSR-E), provided by the VU University Amsterdam together with NASA Goddard Space Flight Centre (Owe et al., 2008). AMSR-E is a passive microwave scanning radiometer, operating at six different wavelengths within the microwave spectrum $(6.925,10.65$, 18.7, 23.8, 36.5, and $89 \mathrm{GHz}$ ). The large area coverage (swath width: $1445 \mathrm{~km}$ ) of the sensor allows for a frequent coverage of the globe in the order of three days with increasing frequencies at higher latitudes. The spatial resolution of the different channels is varying from $5 \mathrm{~km}(89 \mathrm{GHz})$ to $56 \mathrm{~km}(6.925 \mathrm{GHz})$ (Njoku et al., 2003).

Soil moisture retrievals are based on the solution of a microwave radiative transfer model which solves simulta- neously for the surface soil moisture content and vegetation optical depth without a priori information (Meesters et al., 2005). The flexible approach allows in general for the retrieval of soil moisture from a variety of frequencies. The C-band $(6.925 \mathrm{GHz})$ data product is used in the present study as it is expected to have the highest sensitivity to surface soil moisture dynamics from the AMSR-E channels. The data set is available since 2002 and has been validated over a large range of study areas with high correlations with in situ observations in semi arid regions $\left(r=0.79, \mathrm{RMSE}=0.03\left[\mathrm{~m}^{3} / \mathrm{m}^{3}\right]\right.$ for the Murrumbidgee Soil Moisture Monitoring Network in Australia, (Draper et al., 2007); $r=0.83$, RMSE $=0.06\left[\mathrm{~m}^{3} / \mathrm{m}^{3}\right]$ for the REMEDHUS soil moisture network in Spain, (Wagner et al., 2007)) and somewhat lower in agricultural areas $(r=0.78$, RMSE $=0.06\left[\mathrm{~m}^{3} / \mathrm{m}^{3}\right]$ for the SMOS REX site in France, Rdiger et al., 2009).

Only data from the daytime ascending overpass (01:30 p.m.) are used as these were found to be less noisy than the nighttime observations (Loew et al., 2009b). As the sensitivity of the AMSR-E observations to soil moisture decreases with increasing optical depth of the vegetation layer (de Jeu et al., 2008), only data with an optical depth $\tau<0.8$ are used for the further analysis. A single AMSR-E time series, located in the center of the test site (ISEA ID \#2027099) is used in the study.

\section{Soil moisture variability and stability}

The variability of the in situ soil moisture data is analyzed in the following. The investigations are limited to the period from $01 / 05$ to $30 / 10$ of the years 2008 and 2009 to cover a large variability in soil moisture and vegetation conditions, while avoiding interference by snow and frozen soil conditions in the test site.

\subsection{Soil moisture variability}

The average soil moisture $\bar{\theta}$ for the investigated area is calculated from the station data. As the number of stations $(N=5)$ is rather small to sufficiently represent $\bar{\theta}$ this will introduce an uncertainty in the estimation of $\bar{\theta}$ (Famiglietti et al., 2008; Brocca et al., 2010). Figure 2 shows time series of $\bar{\theta}$ and its standard deviation for the years 2008 and 2009 . Both soil moisture curves show a dynamical range between $0.2\left[\mathrm{~m}^{3} / \mathrm{m}^{3}\right]$ and $0.5\left[\mathrm{~m}^{3} / \mathrm{m}^{3}\right]$. The standard deviation varies between 0.025 and $0.1\left[\mathrm{~m}^{3} / \mathrm{m}^{3}\right]$.

\subsection{Temporal stability analysis}

A temporal stability analysis (Sect. 2.1), is conducted for each of the stations, using $\bar{\theta}$ as the reference. For each station and year, the statistic for $\bar{\delta}$ is calculated using (4) and (5). Results are summarized for each station and year in Fig. 3. Considerable differences are observed between the 

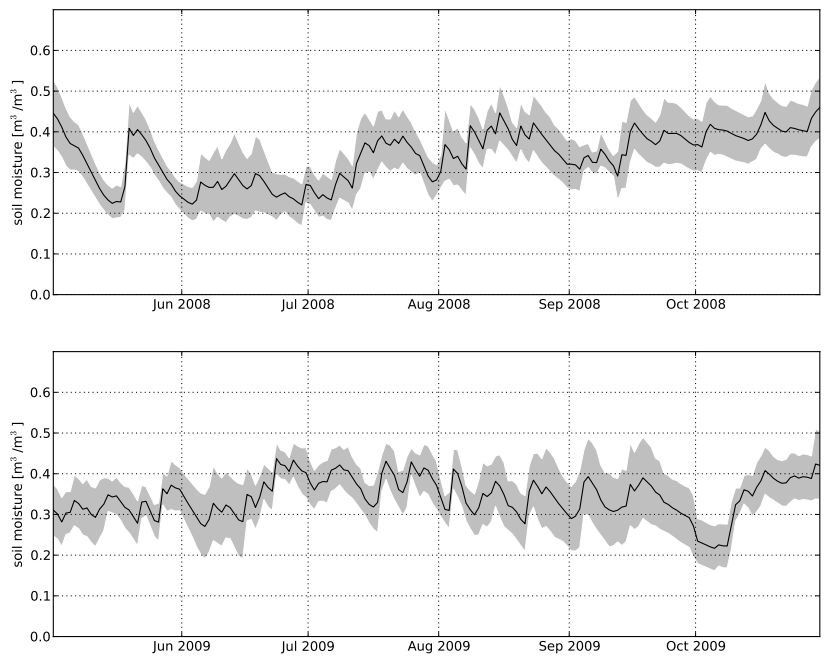

Fig. 2. Temporal evolution of large scale mean soil moisture content $\bar{\theta}$ as calculated from the average of all ground stations. Greyed area correspond to $\pm 1 \sigma_{\theta}$.

years. The station Steinbeissen (Neusling) does best represent the large scale soil moisture dynamics in 2008 (2009) according to the $\bar{\delta}$ metric.

The linear relationship between $\theta_{j}$ and $\bar{\theta}$ was estimated using a least squares approach with $\bar{\theta}$ as the dependent variable. The regression coefficients $m$ and $b$ are given in Table 2. By removing this linear trend, we obtain the random upscaling error for each station $\left(e_{\text {station }}\right)$ as

$e_{\text {station }}=\sqrt{\left\langle(\bar{\theta}-(m \theta+b))^{2}\right\rangle}$

Considerable differences are observed between the two years. The different stations do not show a consistent relationship to the large scale soil moisture dynamics. While all stations show significant correlations with the large area soil moisture dynamics over a certain time period, they might not be used to predict the spatial mean soil moisture dynamics consistently over a longer time period. The reason for these differences are small scale differences in precipitation dynamics, which are mostly related to convective events that are very local.

However at smaller timescales, a single station might be a good predictor for the large scale soil moisture dynamics. We will therefore investigate the potential of using a temporally dynamic approach to assess the soil moisture validation problem by using the TC technique. First, the triple collocation will be applied on an annual basis to provide comparable results with the analysis in the present section. We will then relax the method by applying it on shorter timescales to adapt it to temporally stable soil moisture patterns at shorter timescales.
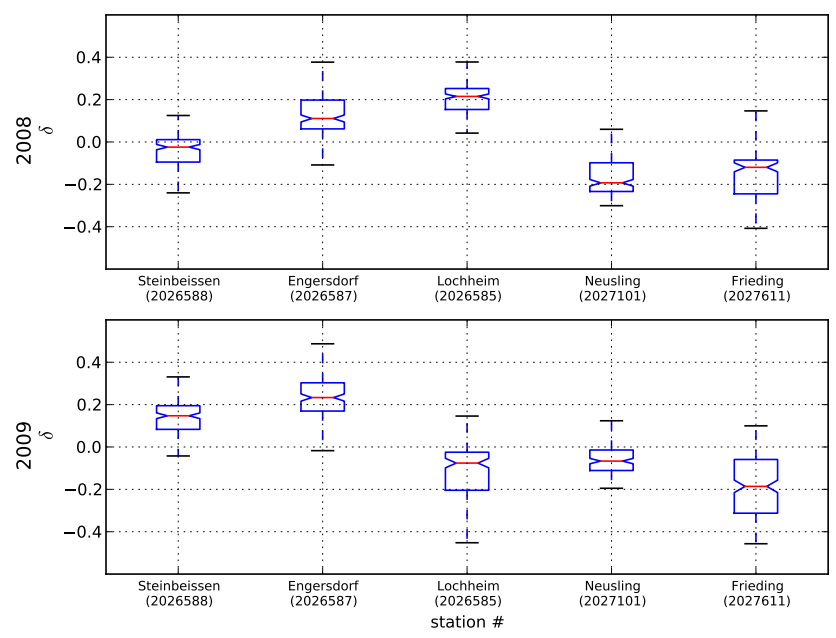

Fig. 3. Boxplot of the relative difference $\bar{\delta}$ between soil moisture observations of a single station and the spatial mean $\bar{\theta}$. Boundaries of the boxes correspond to the $25 \%$ and $75 \%$ quartiles and the line indicates the median value. Whiskers indicate extreme values.

Table 1. List of soil moisture stations, IDs of closest ISEA grid point and assigned experiment number.

\begin{tabular}{rclcc}
\hline $\begin{array}{r}\text { Station } \\
\text { number }\end{array}$ & ISEA & Name & $\begin{array}{c}\text { lat/lon } \\
\text { [deg] }\end{array}$ & experiment \\
\hline 118 & 2026587 & Engersdorf & $48.45 / 12.63$ & 16 \\
74 & 2026585 & Lochheim & $48.27 / 12.49$ & 17 \\
16 & 2026588 & Steinbeissen & $48.61 / 12.73$ & 18 \\
14 & 2027101 & Neusling & $48.69 / 12.88$ & 19 \\
49 & 2027611 & Frieding & $48.34 / 12.83$ & 20 \\
\hline
\end{tabular}

\section{Triple collocation analysis}

\subsection{Data preparation}

The TC method requires all data sets to be temporally collocated. They are therefore binned to daily values and spatially collocated on the ISEA grid. Satellite data which were recorded during precipitation events were not considered for the inter-comparison, as the rainfall and interception in the canopy can deteriorate the microwave signal (Saleh et al., 2007). Such a masking might be in general applicable if in situ measurements of precipitation are available. However, as a consequence of such a masking, the error estimates of the satellite product might be idealized compared to the situation, when no ancillary precipitation data can be used to mask periods that are affected by precipitation. Data from different stations were used as a reference $(x)$ and compared against the spatially averaged soil moisture from PROMET $(y)$ and AMSR-E soil moisture data $(z)$. The different experiments for the various stations are summarized in Table 1. It is assumed that the model and satellite data are representative 
Table 2. Linear regression parameters (gain, offset, correlation coefficient $r$ ) between the soil moisture time series of a station as compared against the corresponding spatial average.

\begin{tabular}{|c|c|c|c|c|c|c|c|c|c|c|}
\hline \multirow{2}{*}{ Station } & \multirow{2}{*}{ Experiment } & \multirow{2}{*}{ ISEA } & \multicolumn{4}{|c|}{2008} & \multicolumn{4}{|c|}{2009} \\
\hline & & & gain $(m)$ & offset $(b)$ & $r$ & $e_{\text {station }}$ & gain $(m)$ & offset $(b)$ & $\mathrm{r}$ & $e_{\text {station }}$ \\
\hline Steinbeissen & 18 & 2026588 & 0.77 & 9.03 & 0.93 & 3.19 & 0.96 & -3.1 & 0.80 & 5.25 \\
\hline Engersdorf & 16 & 2026587 & 0.93 & -1.2 & 0.89 & 4.82 & 0.56 & 10.5 & 0.78 & 8.80 \\
\hline Lochheim & 17 & 2026585 & 0.71 & 4.50 & 0.93 & 8.16 & 0.57 & 16.6 & 0.84 & 5.47 \\
\hline Neusling & 19 & 2027101 & 1.35 & -3.9 & 0.84 & 7.03 & 1.03 & 0.82 & 0.74 & 3.60 \\
\hline Frieding & 20 & 2027611 & 0.72 & 12.6 & 0.90 & 5.95 & 0.51 & 19.8 & 0.72 & 7.87 \\
\hline
\end{tabular}

Table 3. Summary of soil moisture errors as estimated using triple collocation method for different stations: reference station error $\left(e_{\text {station }}\right)$, estimated errors for station, model and satellite $\left(e_{\text {stat }}, e_{\text {model }}, e_{\mathrm{sat}}\right)$, correlation $(r)$, gains $\beta$ and offsets $\alpha$ of the relationships given by (6). Upscaling errors for the station used as variable $x$ is shown for comparison $\left(e_{\text {station }}\right)$. Errors are given as $\left[\mathrm{m}^{3} / \mathrm{m}^{3}\right] \times 100$.

\begin{tabular}{ccc|cccccccrrr}
\hline Year & Exp. & $e_{\text {station }}$ & $e_{\text {stat }}$ & $e_{\text {model }}$ & $e_{\text {sat }}$ & $r_{\text {station,model }}$ & $r_{\text {station,AMSR-E }}$ & $r_{\text {model,AMSR-E }}$ & $\beta_{1}$ & $\alpha_{1}$ & $\beta_{2}$ & $\alpha_{2}$ \\
\hline \multirow{6}{*}{2008} & 16 & 2.83 & 2.68 & 2.66 & 5.96 & 0.88 & 0.51 & 0.37 & 0.55 & 4.86 & 0.48 & 16.9 \\
& 17 & 3.23 & 4.49 & 2.85 & 5.80 & 0.85 & 0.53 & 0.35 & 0.34 & 11.6 & 0.32 & 22.0 \\
& 18 & 2.66 & 0.97 & 2.82 & 5.87 & 0.76 & 0.48 & 0.36 & 0.43 & 11.9 & 0.41 & 21.9 \\
& 19 & 3.23 & 1.19 & 2.49 & 5.92 & 0.78 & 0.42 & 0.36 & 0.95 & -0.7 & 0.78 & 13.6 \\
& 20 & 3.56 & 4.89 & 1.76 & 5.44 & 0.74 & 0.46 & 0.51 & 0.55 & 9.29 & 0.53 & 21.4 \\
\hline \multirow{2}{*}{2009} & 16 & 2.92 & 4.87 & 1.38 & 4.88 & 0.47 & 0.17 & 0.27 & 0.72 & -2.7 & 0.51 & 11.7 \\
& 17 & 2.52 & 1.56 & 2.29 & 6.20 & 0.63 & 0.42 & 0.25 & 0.24 & 20.5 & 0.39 & 24.0 \\
& 18 & 2.48 & 2.00 & 2.17 & 5.63 & 0.68 & 0.64 & 0.32 & 0.39 & 12.5 & 0.94 & -2.0 \\
& 19 & 2.80 & 2.06 & 2.38 & 4.70 & 0.60 & 0.43 & 0.18 & 0.36 & 16.1 & 0.48 & 19.1 \\
& 20 & 3.13 & 4.02 & 0.75 & 6.50 & 0.75 & 0.23 & 0.28 & 0.55 & 12.6 & 0.40 & 24.2 \\
\hline
\end{tabular}

for the same spatial domain, while the ground measurements are expected to provide an uncertain proxy for $\bar{\theta}$ over the same area. We aim to obtain a robust estimate for the satellite soil moisture error $\left(e_{\text {sat }}^{2}=\left\langle e_{z}^{2}\right\rangle\right)$ to quantify the accuracy of the satellite data.

The triple collocation analysis will be either made for the entire investigation period (01/05-30/10) or for a 30 day moving window from the beginning to the end of the investigation period with steps of 15 days. The TC method presumes that the three data sets used in the analysis represent the same geophysical quantity. A correlation analysis is therefore used to investigate this purpose by calculating the correlation between each pair of $x, y, z$. In case of negative correlation, the data are not analyzed. Scipal et al. (2009) further screened the data by applying a threshold of 0.2 to the obtained correlation coefficient which corresponds to a significant correlation at the $95 \%$ level for time series with a large number of samples. However, as we restrict our analysis to much shorter timescales, we explicitly calculate the significance $\left(p_{\mathrm{xy}}, p_{\mathrm{xz}}, p_{\mathrm{yz}}\right)$ of the correlation between the variables according to a t-test (Press et al., 1992). Nevertheless, it is emphasized that the correlation analysis provides only a statistical measure of the relationship between the different data sets. However, if the signal to noise ratio in the analyzed data is high, correlation might be very low, but the
TC method might neverless be able to provide realistic error estimates.

\subsection{Analysis results}

The TC analysis is made in two parts. First, results from a yearly analysis are presented (static approach) which are followed by results from the TC analysis at shorter time scales (dynamic approach).

\subsubsection{Static triple collocation approach}

The static approach exploits the full time series for the estimation of the error variances, which is similar to the approach of Scipal et al. (2009). The estimated errors for the model simulated and satellite soil moisture show consistent results for the different experiments (Table 3 ). The model errors $\left(e_{\text {model }}\right)$ range between 0.0176 and $0.0285(0.0075$ and $0.0238)\left[\mathrm{m}^{3} / \mathrm{m}^{3}\right]$ for 2008 (2009). The AMSR-E soil moisture error $\left(e_{\mathrm{sat}}\right)$ ranges between 0.047 and $0.0659\left[\mathrm{~m}^{3} / \mathrm{m}^{3}\right]$ which is in the same order than results obtained from previous studies (Draper et al., 2007; Wagner et al., 2007). The robust results for the satellite product error for different stations indicate that the selection of a particular station seems to have minor impact on the uncertainty estimates. 

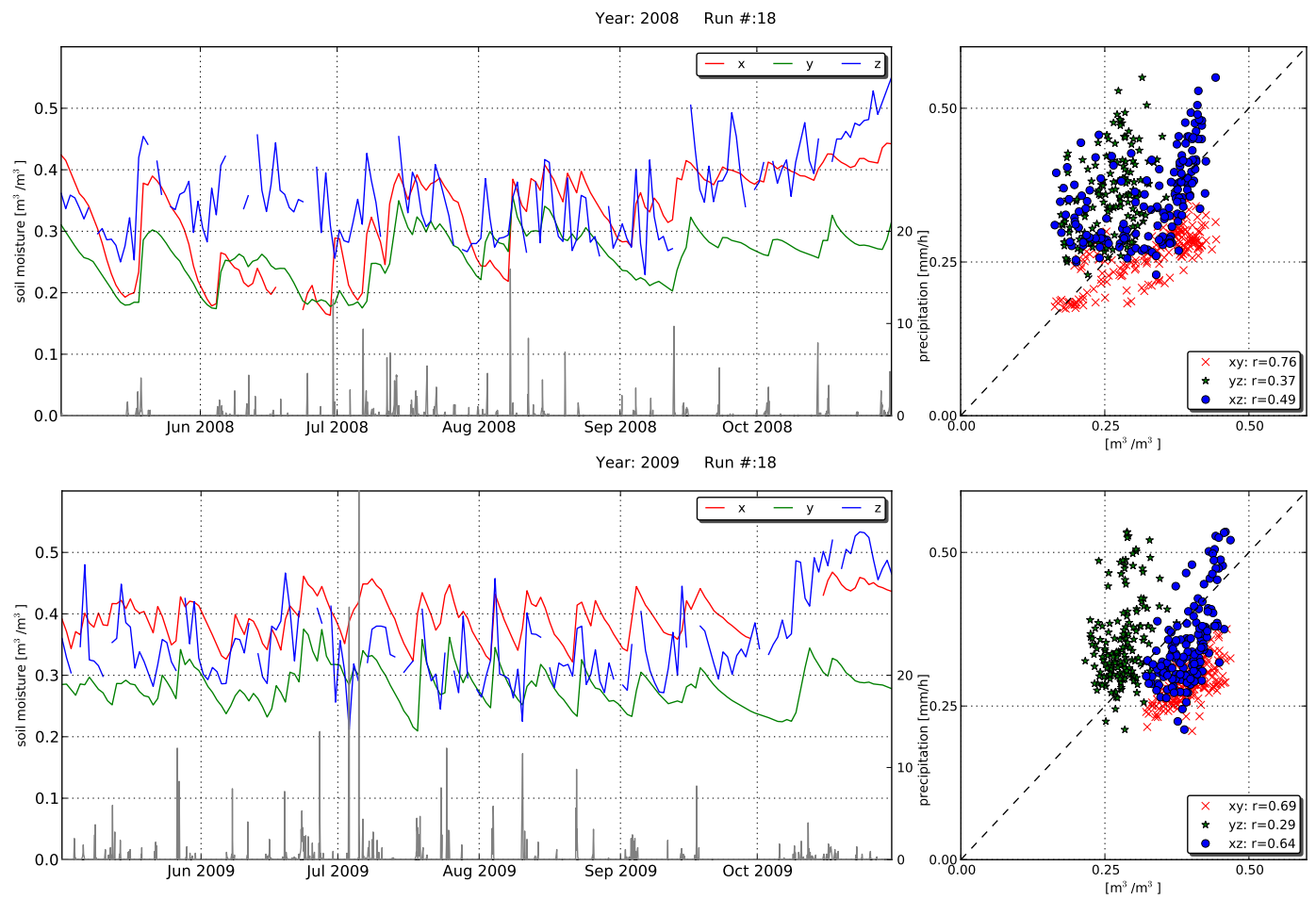

Fig. 4. Soil moisture time series for the station Steinbeissen \#18 (red) and the corresponding model and satellite soil moisture time series. Precipitation information (grey bars). Scatterplot illustrates correlation between the different data tuples (x:station,y:model,z:AMSR-E).

All stations show significant correlations between the in situ measurements and the model simulations as well as the satellite retrievals. Further it is observed that the correlation between the station and the satellite data is in general higher than the correlation between the model and the satellite data.

As the same model and satellite data are used for all simulations, differences in the error estimates result only from differences between the ground stations. Their representativity for the large scale soil moisture dynamics changes throughout the year as was shown previously.

The estimated gains $\left(\beta_{1}, \beta_{2}\right)$ vary between 0.22 and 0.86 which would have been expected due to the lower spatially aggregated soil moisture variability at larger scales compared to local measurements. Different gains are observed for the same station in different years. A comparison of the estimated error for each station $\left(e_{\text {stat }}\right)$ with the actual estimate of the station error $\left(e_{\text {station }}\right)$ shows that they are in the range between 0.0248 and $0.0356\left[\mathrm{~m}^{3} / \mathrm{m}^{3}\right]$ for $e_{\text {stations }}$ and 0.0097 and $0.0489\left[\mathrm{~m}^{3} / \mathrm{m}^{3}\right]$ for $e_{\text {stat }}$ (Table 3).

Considerable differences are observed between the two years for the various stations. These results indicate that data from the different stations can not be used to upscale the local soil moisture measurements in a consistent way as their representativeness for the larger area is changing with time, which is consistent with the results of the temporal stability analysis. This indicates that temporally adaptive methods are needed for the inter-comparison of the in situ soil moisture data with the footprint scale soil moisture estimates. This is at least valid for the data used in the present analysis. We will therefore investigate in the following if a dynamic TC approach, applied on shorter timescales, might be used as an alternative for the soil moisture validation problem.

\subsubsection{Dynamic triple collocation approach}

A temporal moving window of $\Delta t=30$ days is used for the dynamic triple analysis which reduces the number of collocated data points and thus the degree of freedom for the correlation between the data tuples. As the analysis window is shifted by 15 days, we obtain a 15 day overlap between the different analysis periods. The results of all different 30-day intervals are summarized in Figs. 5-7. These show the temporal variability of $r, e$ and $\beta$. Data sets, where the correlation for at least one out of the three data tuples $(x y, x z, y z)$ was not significant at the $95 \%$ level are marked with gray bars. Dashed lines correspond to $e, r, \beta$ as estimated from the static TC approach in the previous section and are provided for comparison.

The estimated satellite product errors are in general lower for the dynamic approach than they are for the static TC analysis. The obtained values for $e_{\text {sat }}$ are consistent between the different stations and show a similar temporal dynamic which indicates that the choice of the reference station has 
Correlation

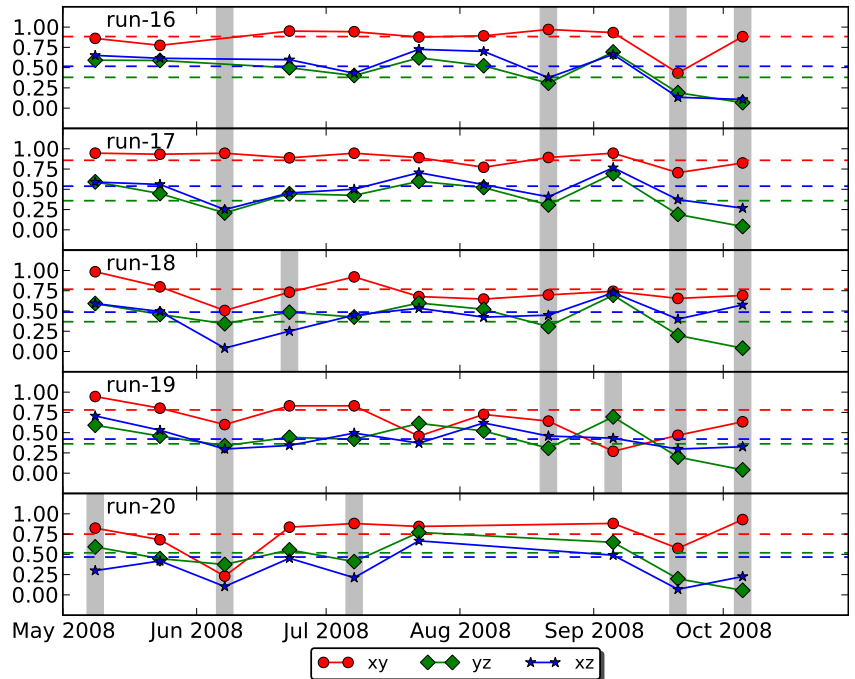

Correlation

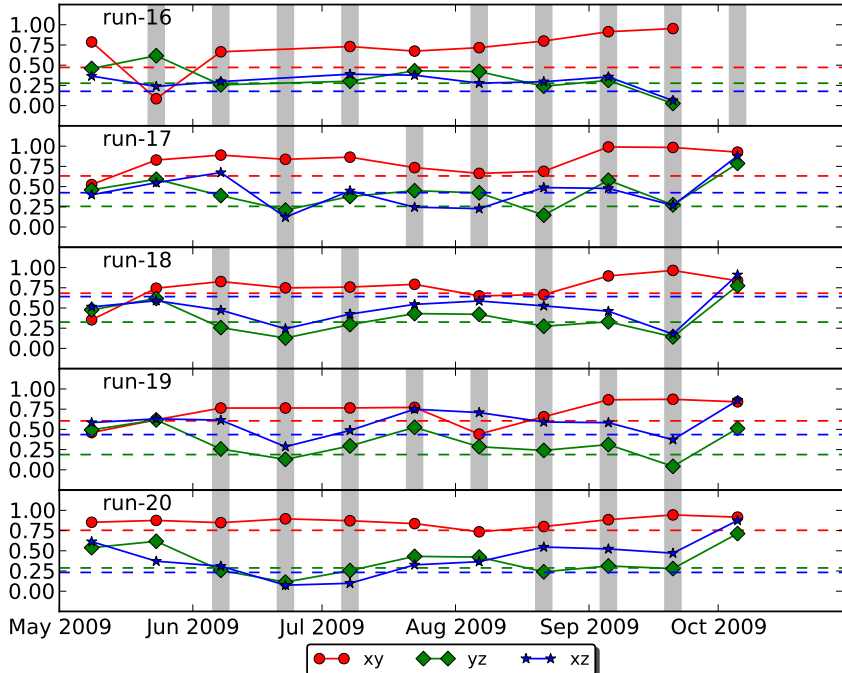

Fig. 5. Correlation coefficients for dynamic TC analysis with $d T=30$ days for relationship between station and model (xy,red), model and satellite (yz,green) and station and satellite (xz,blue) for the years 2008 and 2009. Dates correspond to center of analyzed time period. Grey bars indicate cases where at least one of the correlations was not significant at the $95 \%$ level.

Gains

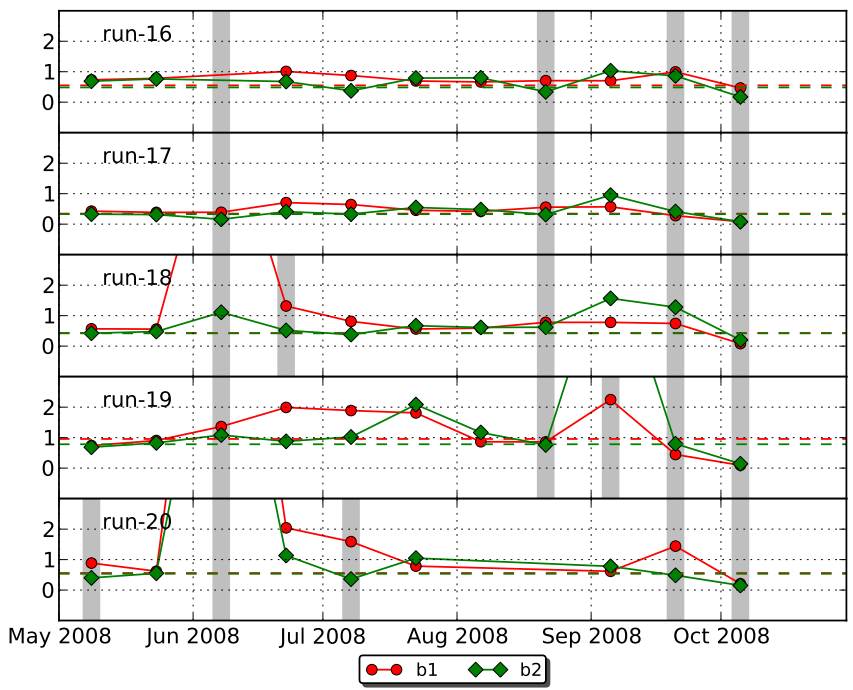

Gains

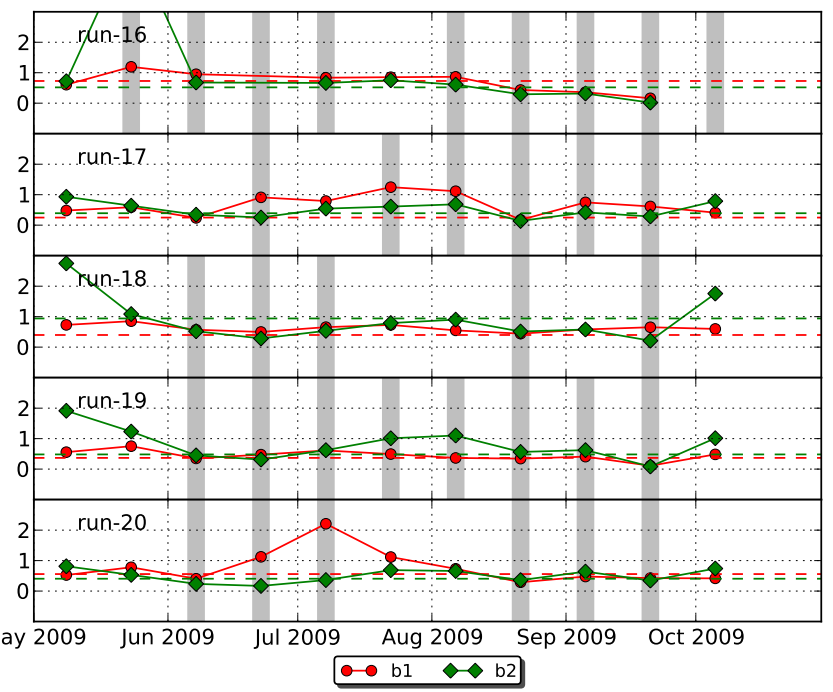

Fig. 6. Same as Fig. 5 but for gains $\left(\beta_{1}, \beta_{2}\right)$ from (6).

a minor effect on the calculation of $e_{\text {sat }}$ and that they provide a robust estimate of the uncertainty of the satellite data product.

In a large number of sample intervals non-significant correlations are found. In general, one can differentiate between time intervals where all stations show a non-significant correlation between at least one of the data tuples and those where a single station indicates a correlation at a low significance level. As an example, Fig. 8 shows details of the analyzed time series for the stations \#17 (Lochheim) and \#18 (Steinbeissen) for consecutive time periods in 2008 .

All three data sets capture well the decrease of soil moisture until mid of May 2008 and the increase due to the precipitation between 16th and 19th of May 2008 (a). Highly significant correlations are found between all data tuples. Frequent precipitation in the first half of June results in a couple of data gaps for the satellite data due to the precipitation masking, decreasing especially the correlation between 
Errors

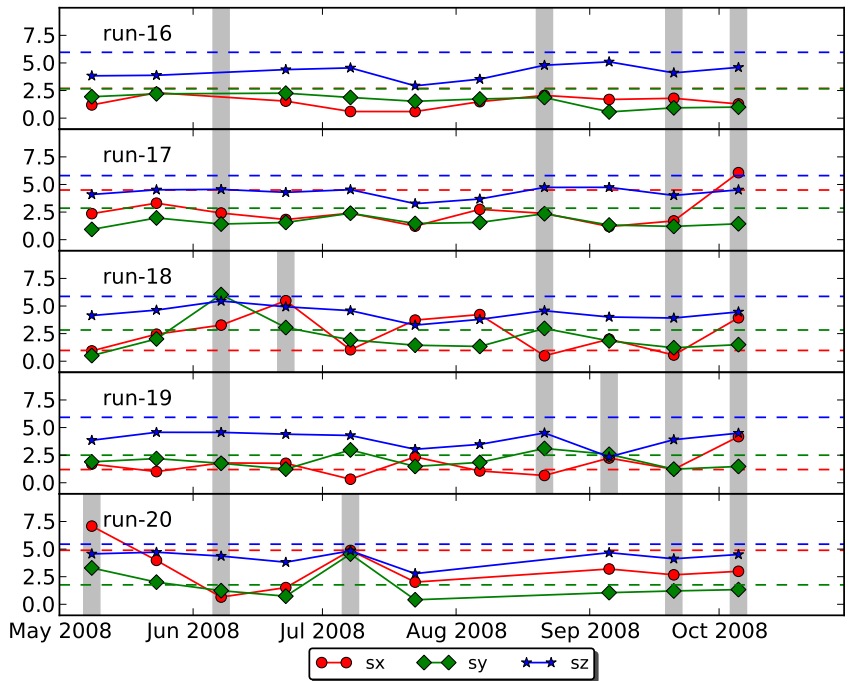

Errors

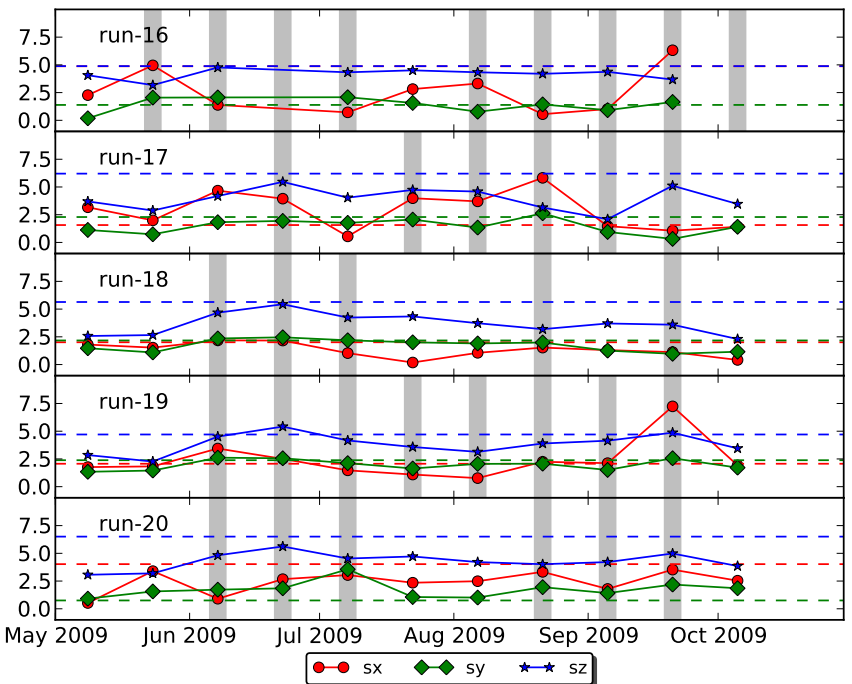

Fig. 7. Same as Fig. 5 but for estimated errors of station (sx,red), model (sy,green) and satellite (sz,blue).

the satellite data and model results (b). The following time period is dominated by low soil moisture dynamics until end of June (c). The satellite data capture in general this low variability, but no significant correlations with neither the PROMET model simulations nor the in situ data are found for this period for both stations. The satellite soil moisture product has large noise compared to the small soil moisture signal. The satellite data capture the increase of soil moisture after 10th of July 2008 (d) for both stations although there are data gaps during this rain period. However, no significant correlations are found between the in situ data and the satellite product for station \#18 ( $p=0.74)$, while significant correlations are found for station \#17 (e). This station is the only one that shows no significant correlations during that time period (see also Fig. 7). In this case, the lack of a significant correlation is caused by a data gap in the in situ soil moisture data from 17 th to 23 th of June which has been identified by the TC method.

\subsubsection{Effect of temporal sampling}

The temporal window used for the dynamic TC analysis determines how many data points are used in the analysis and thus determines the degree of freedom for the correlation. The previous analysis with $\Delta t=30$ days did show that an analysis on short time scales is feasible and helps to make an appropriate error assessment of the satellite data. The significance of the correlations between the time series has been shown to be a useful tool for the detection of gaps and artefact's in the time series. However, large parts of the time series show no significant correlation at the $95 \%$ level in these cases.
On the other hand, the yearly analysis did show significant correlations for all data tuples as a larger time interval results in a higher degree of freedom for the correlation threshold. A further analysis using $\Delta t=60$ [days] (not shown here) did show very consistent results for the satellite error as estimated from different stations. The estimated satellite error was smaller than the one obtained from the yearly analysis, but did show less temporal variability than the one obtained using $\Delta t=30$ [days]. However, the low soil moisture variability in the mid of June 2008 does still affect this analysis and non-significant correlations are identified for all stations during that time period using $\Delta t=60$ [days] which provides additional information on the lack of significant information on soil moisture dynamics in the remote sensing data.

\subsubsection{Accuracy of error quantification}

To assess the reliability of these estimates, we compare $e_{\text {sat }}$ against the reference error $e_{\text {station. }}$. The latter is an approximation to the actual uncertainties in representing large scale soil moisture dynamics using a single station, as has been discussed previously. In case that the TC method provides good predictive skills for the actual error of a station it should also provide reliable estimates of the error of the satellite product.

Figure 9 shows a comparison between the results of the error analysis for the two years. Each point corresponds to a single triple collocation result of a 30 day period and a single station. The different number of points per station and year results from the fact that only periods with significant correlations ( $95 \%$ confidence) between the data sets have been used. The root mean square deviation (RMSD) between the estimated and reference error is $0.00841(0.00835)\left[\mathrm{m}^{3} / \mathrm{m}^{3}\right]$ in 2008 (2009). These results are very close to the results 

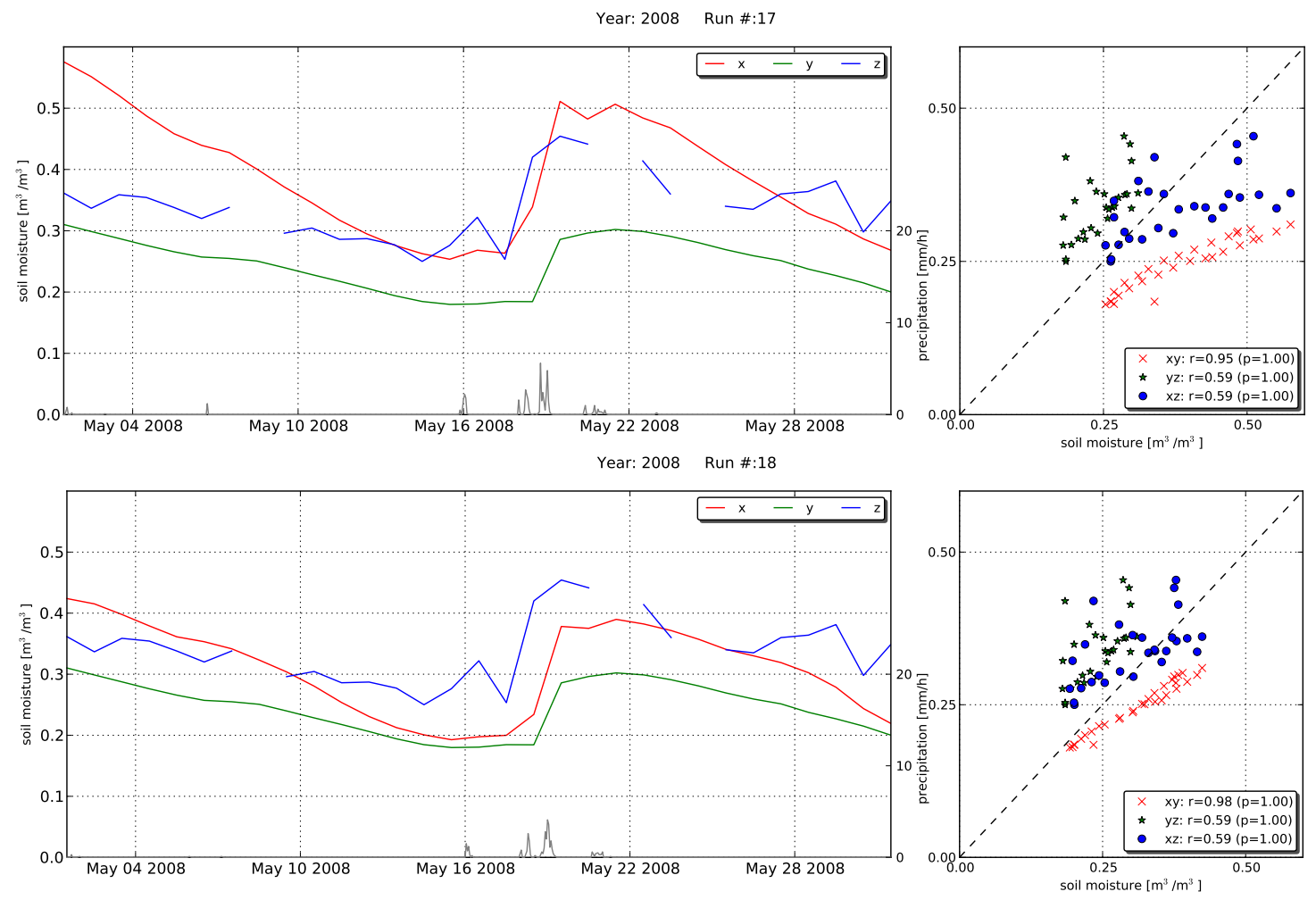

Fig. 8a. Details of soil moisture time series for stations Lochheim \#17 and Steinbeissen \#18 (red), model (green) and satellite (blue). Correlations $r$ between the time series and their respective significance $p$ are provided. Information on precipitation dynamics is provided (x:station,y:model,z:AMSR-E).

obtained by (Miralles et al., 2010) who found that the triple collocation methods could provide error estimates with an accuracy between $0.00694\left[\mathrm{~m}^{3} / \mathrm{m}^{3}\right]$ and $0.0150\left[\mathrm{~m}^{3} / \mathrm{m}^{3}\right]$ using data from different test sites. It is very encouraging that the obtained error estimates are close to those estimated from the in situ data and those obtained by Miralles et al. (2010) who conducted their study in completely different test sites with different soil moisture dynamics. However, Miralles et al. (2010) estimated their errors using an anomaly approach, by removing a running mean 31-day average from the original time series to obtain longterm errors. The proposed dynamic TC approach is therefore somewhat different and even more challenging as it attempts to retrieve the errors from shorter time periods. However, while the dynamic TC is technically different, the adaptive rescaling resulting from the TC approach might be somehow considered to be similar to the removal of a climatological mean value.

\section{Discussion and conclusions}

The present study did investigate different approaches for the inter-comparison of coarse scale remote sensing soil moisture data with in situ measurements on soil moisture dynamics. The temporal stability approach was found to be not appropriate for the data set used, while it could be shown that the TC method provides very promising estimates of the random errors of different soil moisture data sets at different temporal scales.

The TC method was successfully applied to quantify the uncertainties of AMSR-E soil moisture data in the Upper Danube catchment. While temporary persistent soil moisture patterns could be identified in the test site, no single soil moisture station was found to provide a robust proxy for the large scale soil moisture dynamics within the test site.

Combining single location in situ data with land surface model simulations and remote sensing soil moisture estimates using the static TC method did provide consistent estimates of the error of the satellite soil moisture product. The rescaling of the soil moisture data in the TC analysis compensates for systematic differences between the various data sets. The spatially averaged long term AMSR-E soil moisture RMSE was estimated as $0.057\left[\mathrm{~m}^{3} / \mathrm{m}^{3}\right]$. The such obtained satellite product uncertainties are very valuable to provide a general estimate of the quality of the data product from a user's point of view.

However, the analysis of satellite soil moisture products at shorter timescales provides additional quantitative information on the temporal dynamics of its error. The proposed dynamic TC method compensates for the lack of represen- 

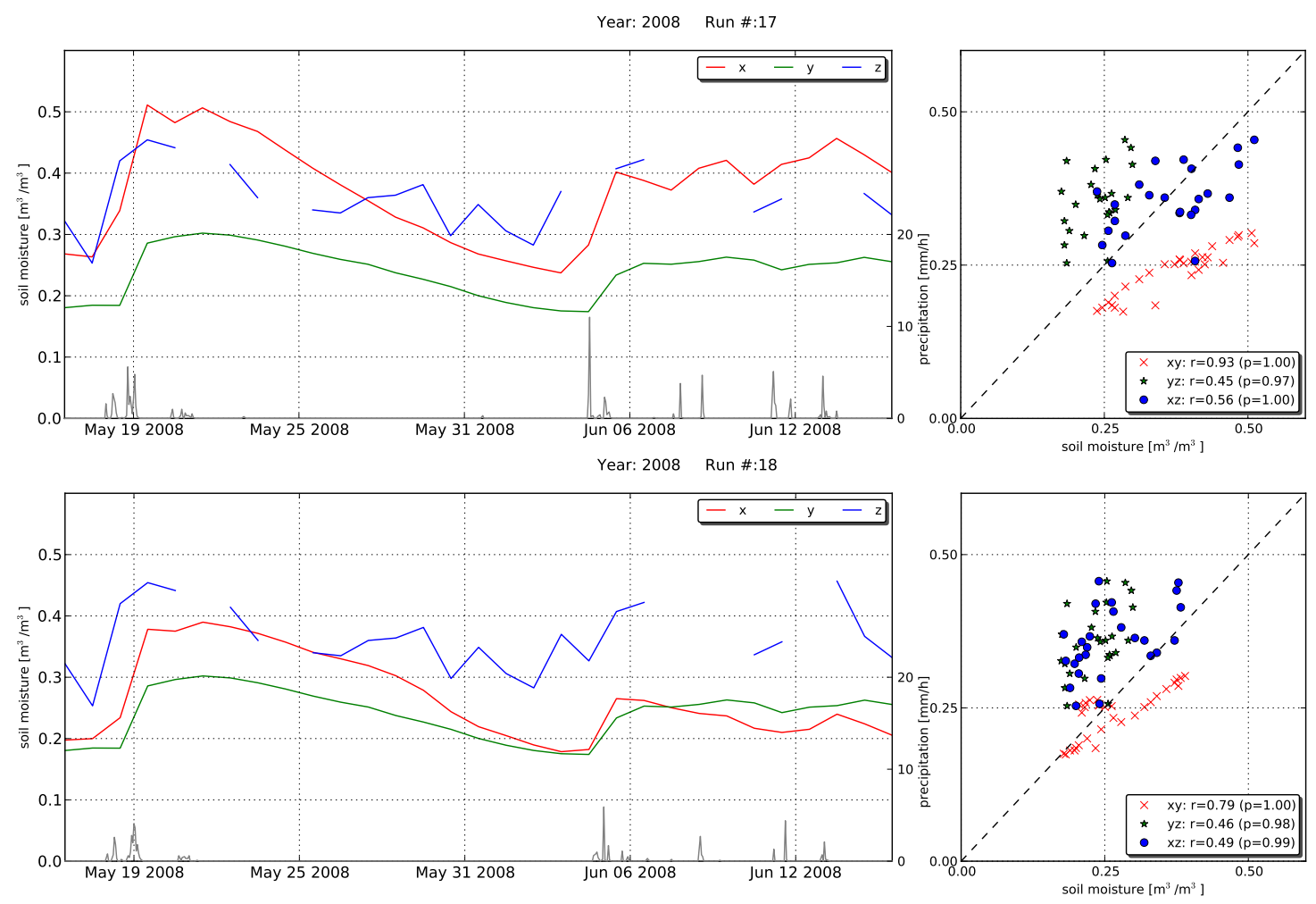

Fig. 8b. Continued.
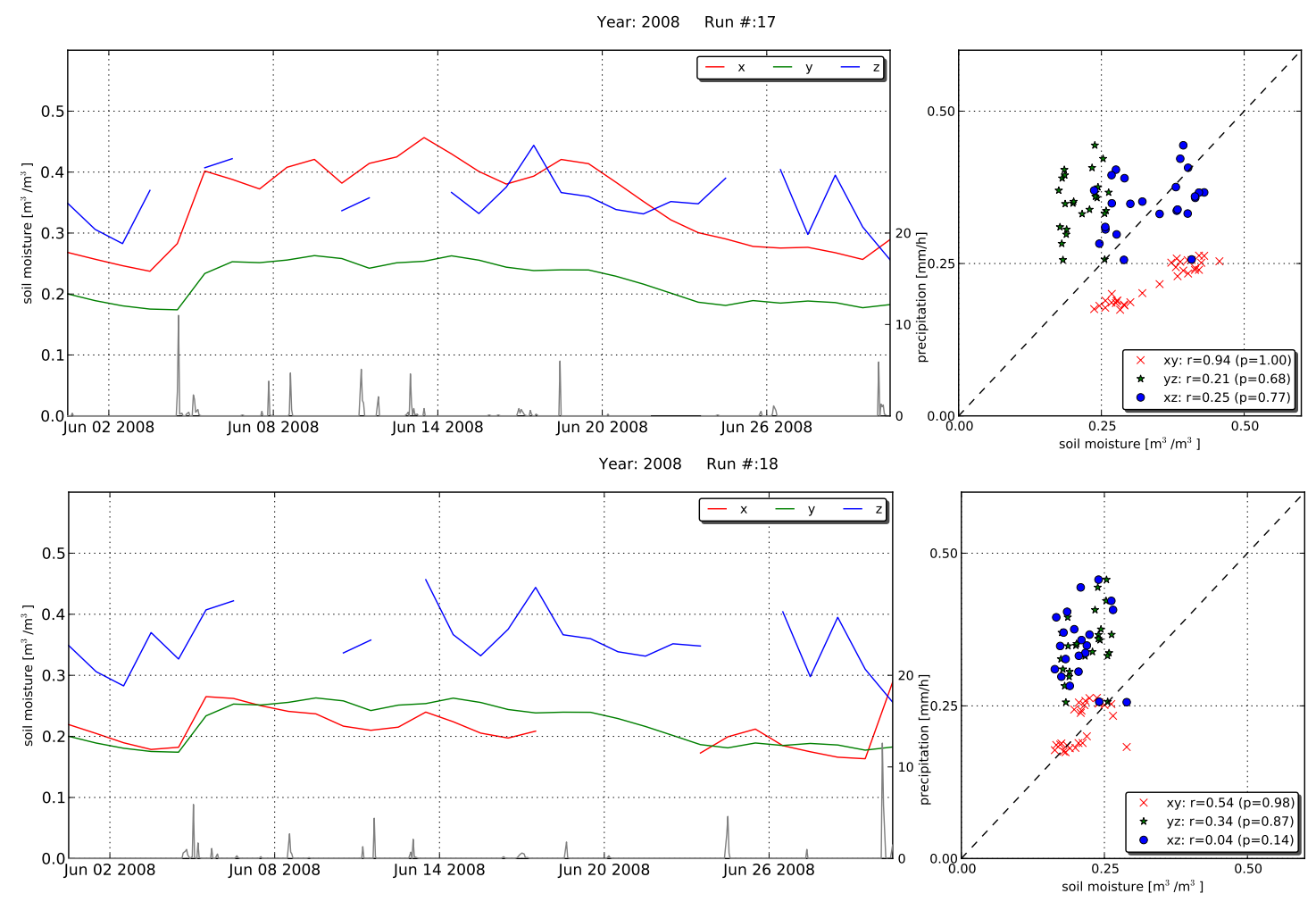

Fig. 8c. Continued. 

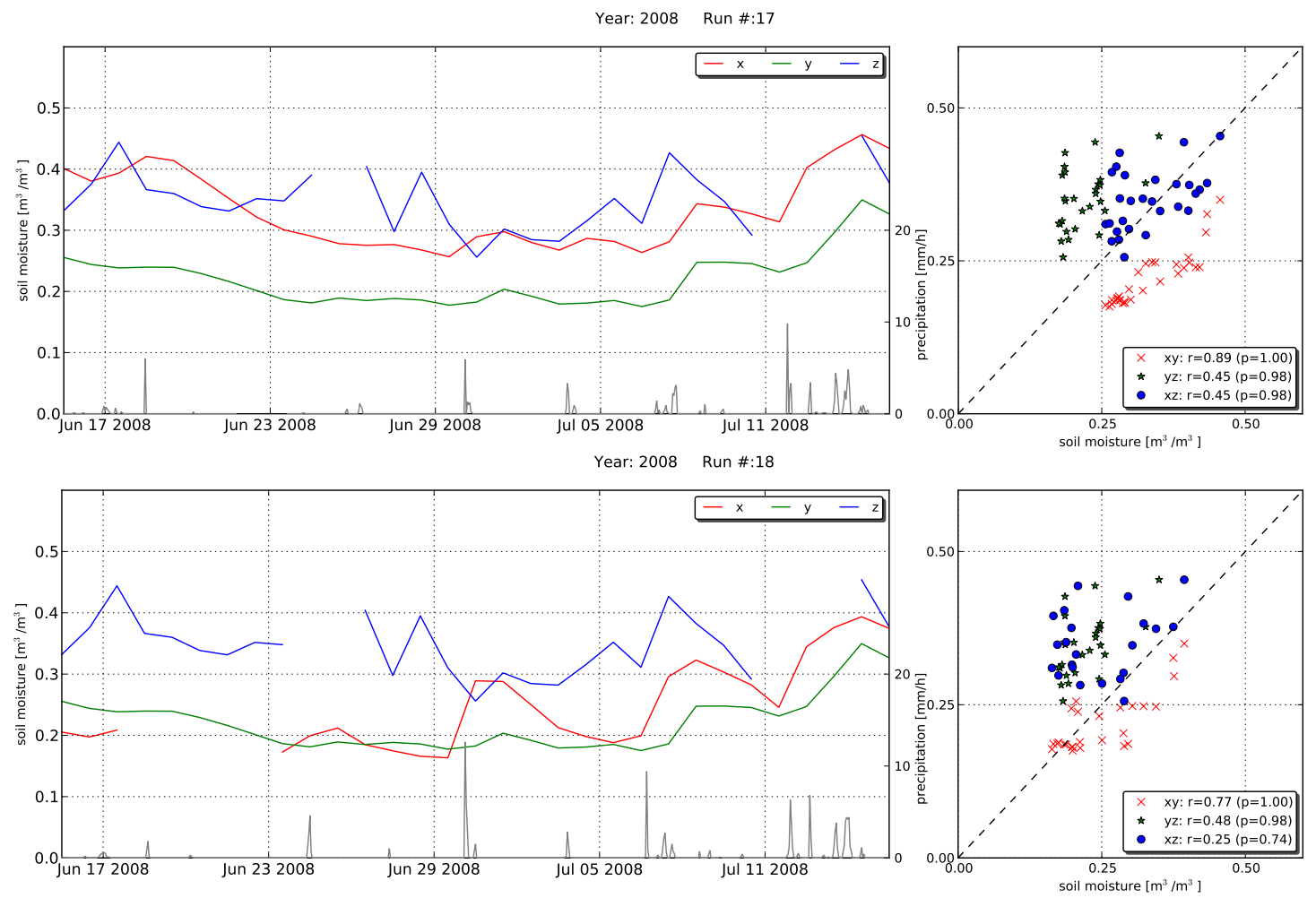

Fig. 8d. Continued.
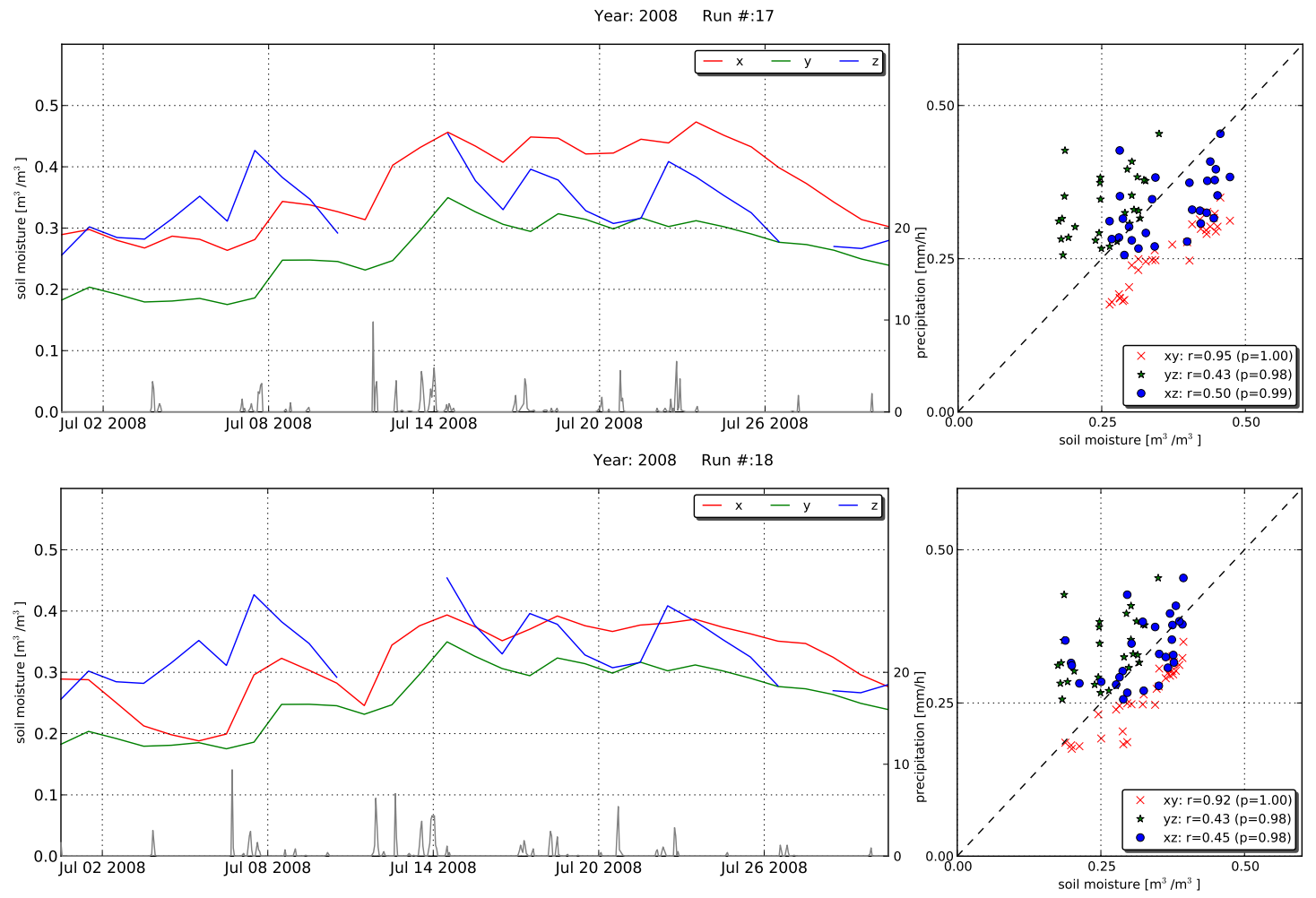

Fig. 8e. Continued. 

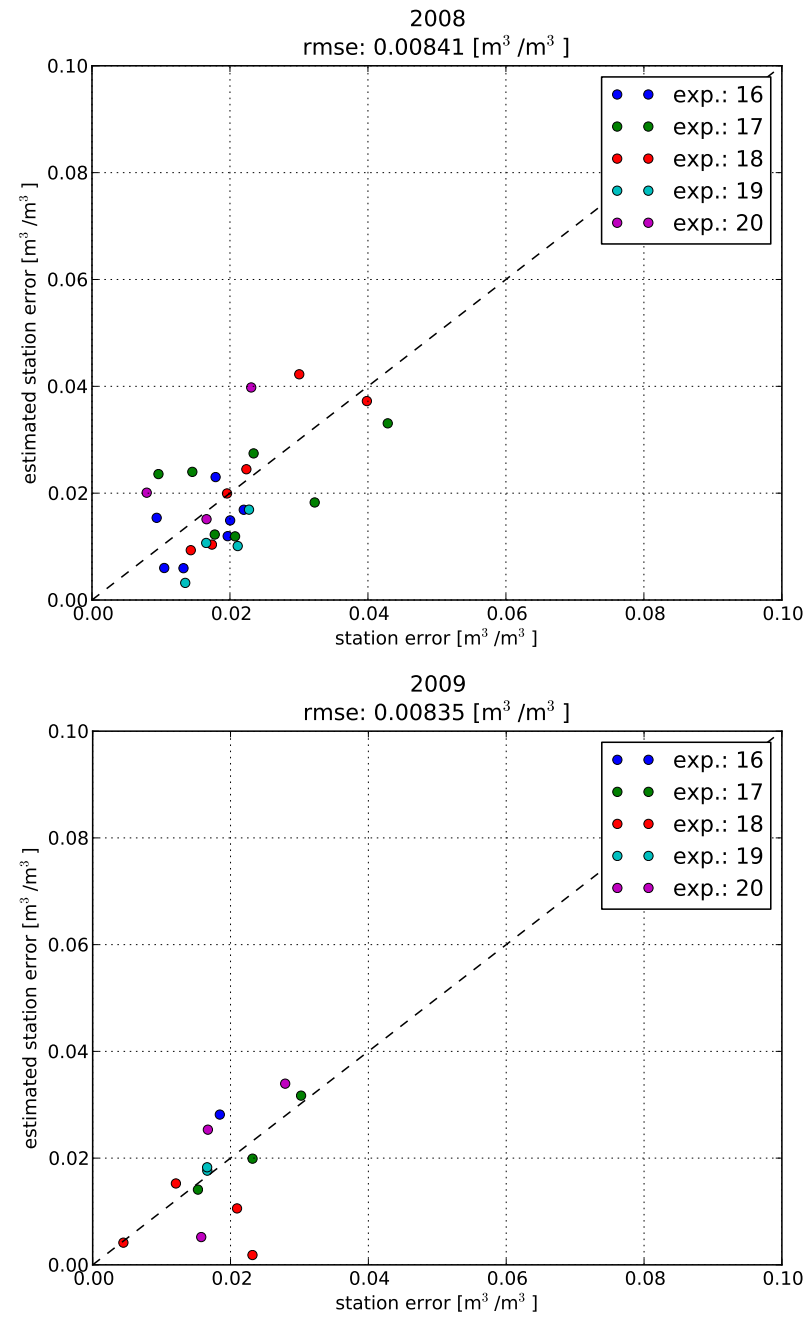

Fig. 9. Comparison of the estimated station error $\left(e_{\text {stat }}\right)$ with the reference soil moisture error $\left(e_{\text {station }}\right)$ for the years 2008 and 2009 using periods with significant correlations between all soil moisture data sets. Different colors correspond to different stations.

tativeness of a single soil moisture station by taking into account the temporal varying relationships between in situ and satellite soil moisture dynamics.

Consistent satellite error estimates were obtained using data from different soil moisture stations as a reference. The such obtained errors were smaller than those estimated from the long term static TC approach which indicates that the satellite product can have a higher accuracy in specific periods than those estimated from the annual analysis. Significant correlations between the used soil moisture data sets were found at these shorter timescales as well. The significance of these correlations provides important additional information on the quality of the error estimates. It could be shown that increasing uncertainties of the satellite soil moisture product are reflected in a decrease of the significance of the correlation.

Time periods with higher errors of the satellite data product could be clearly identified when the analysis from several stations did show non-significant correlations. In case that only a single station did show a non-significant correlation, we could show that this is an indicator for a reduced quality of the reference data. Thus, there is a strong need for using multiple in situ soil moisture stations for the validation of remote sensing satellite products in a test site as these provide complementary information for the evaluation of the TC results.

In practice, periods without significant soil moisture information could not be identified without appropriate reference soil moisture information. The obtained error estimates therefore represent a lower boundary of the possible range of soil moisture errors, while the annual TC method (static) provides the upper limit. The actual soil moisture error is therefore likely to range somewhere in between these two extremes. However, in case of a low signal-to-noise ratio (SNR) as it might occur under constant dry conditions, the correlations might be very low, while the TC method might still be able to provide correct error estimates.

The dynamic TC method thus provides additional information on the accuracy of the satellite data product as well as the reference soil moisture data which is in particular useful for improving the validation and further development of remote sensing soil moisture products. The accuracy of the calculated soil moisture errors was estimated as $0.0084\left[\mathrm{~m}^{3} / \mathrm{m}^{3}\right]$ for the used soil moisture stations.

The triple collocation method provides a useful framework for the quantification of errors of satellite soil moisture products. The proposed extension to shorter timescales makes it a useful tool for a more detailed quantitative analysis of satellite soil moisture time series and their validation. The method is in general applicable to time series of different satellites as well as different geophysical variables. A further evaluation of the method in other test sites as well as an extension of the method to SMOS soil moisture data products is foreseen.

Acknowledgements. Alexander Loew was supported through the Cluster of Excellence CliSAP (EXC177), University of Hamburg, funded through the German Science Foundation (DFG) which is gratefully acknowledged. Field data collection and model simulations were conducted in the frame of the SMOSHYD project, funded by the German Aerospace Center (50EE0731). AMSR-E soil moisture products were obtained from the Vrije Universiteit Amsterdam. We would like to thank the reviewers and W. Crow for their constructive comments on a previous version of the manuscript.

The service charges for this open access publication have been covered by the Max Planck Society

Edited by: W. Wagner 


\section{References}

Albergel, C., Calvet, J.-C., Mahfouf, J.-F., Rüdiger, C., Barbu, A. L., Lafont, S., Roujean, J.-L., Walker, J. P., Crapeau, M., and Wigneron, J.-P.: Monitoring of water and carbon fluxes using a land data assimilation system: a case study for southwestern France, Hydrol. Earth Syst. Sci., 14, 1109-1124, doi:10.5194/hess-14-1109-2010, 2010.

Bindlish, R. and Barros, A. P.: Multifrequency Soil Moisture Inversion from SAR Measurements with the Use of IEM, Remote Sens. Environ., 71, 67-88, 2000.

Brocca, L., Morbidelli, R., Melone, F., and Moramarco, T.: Soil moisture spatial variability in experimental areas of central Italy, J. Hydrol., 333, 356-373, doi:10.1016/j.jhydrol.2006.09.004, http://dx.doi.org/10.1016/j.jhydrol.2006.09.004, 2007.

Brocca, L., Melone, F., Moramarco, T., and Morbidelli, R.: Spatialtemporal variability of soil moisture and its estimation across scales, Water Resour. Res., 46, W02516+, http://dx.doi.org/10. 1029/2009WR008016, doi:10.1029/2009WR008016, 2010.

Brock, F., Crawford, K. C., Elliott, R. L., Cuperus, G. W., Stadler, S. J., Johnson, H. L., and Eilts, M. D.: The Oklahoma Mesonet: A Technical Overview, Journal Atmos. Oceanic TEchnol., 12, 5-19, 1995.

Brooks, R. and Corey, A.: Hydraulic properties of porous media, Tech. rep., Hydrology paper 3, Colorado State University, Fort Collins, Colorado, 1964.

Caires, S. and Sterl, A.: Validation of ocean wind and wave data using triple collocation, J. Geophys. Res., 108, C3, doi:10.1029/2002JC001491, 2003.

Ceballos, A., Martinez-Fernandez, J., Santos, F., and Alonso, P.: Soil-water behaviour of sandy soils under semi-arid conditions in the Duero Basin (Spain), J. Arid Environ., 51, 501-519, 2002.

Clark, C. and Arritt, R.: Numerical simulations of the effect of soil moisture and vegetation cover on the development of deep convection, J. Appl. Meteorol., 34, 2029-2045, 1995.

Cosh, M. H., Jackson, T. J., Bindlish, R., and Prueger, J. H.: Watershed scale temporal and spatial stability of soil moisture and its role in validating satellite estimates, Remote Sens. Environ., 92, 427-435, 2004.

Cosh, M. H., Jackson, T. J., Starks, P., and Heathman, G.: Temporal stability of surface soil moisture in the Little Washita River watershed and its applications in satellite soil moisture product validation, J. Hydrol., 323, 168-177, 2006.

de Jeu, R., Wagner, W., Holmes, T., Dolman, A., van de Giesen, N., and Friesen, J.: Global Soil Moisture Patterns Observed by Space Borne Microwave Radiometers and Scatterometers, Surveys in Geophysics, 29, 399-420, http://dx.doi.org/10.1007/ s10712-008-9044-0, doi:10.1007/s10712-008-9044-0, 2008.

Draper, C., Walker, J., Steinle, P., de Jeu, R., and Holmes, T.: Remotely sensed soil moisture over Australia from AMSR-E, Proceedings, MODSIM 2007International Congress on Modelling and Simulation, Christchurch, New Zealand, Modelling and Simulation Society of Australia and New Zealand, 2007.

Entekhabi, D., Njoku, E. G., O’Neill, P. E., Kellogg, K. H., Crow, W. T., Edelstein, W. N., Entin, J. K., Goodman, S. D., Jackson, T. J., Johnson, J., Kimball, J., Piepmeier, J. R., Koster, R. D., Martin, N., McDonald, K. C., Moghaddam, M., Moran, S., Reichle, R., Shi, J. C., Spencer, M. W., Thurman, S. W., Tsang, L., and Zyl, J. V.: The Soil Moisture Active Passive (SMAP) Mission, Proceedings of the IEEE, 98, 704-716, 2010.
Famiglietti, J. S., Ryu, D., Berg, A. A., Rodell, M., and Jackson, T. J.: Field observations of soil moisture variability across scales, Water Resources Research, 44, W01423+, http://dx.doi.org/10. 1029/2006WR005804, doi:10.1029/2006WR005804, 2008.

Fast, J. D. and McCorcle, M. D.: The effect of heterogeneous soil moisture on a summer baroclinic circulation in the central United States, Mon. Weather Rev., 119, 2140-2167, 1991.

Grayson, R. and Western, A.: Towards areal estimation of soil water content from point measurements: time and space stability of mean response, J. Hydrol., 207, 68-82, 1998.

Jackson, T., Cosh, M., Bindlish, R., Starks, P., Bosch, D., Seyfried, M., Goodrich, D., Moran, S., and Du, D.: Validation of Advanced Microwave Scanning Radiometer soil moisture products, IEEE T. Geosci. Remote., in press, 2010.

Jackson, T. J., Bindlish, R., Gasiewski, A., Stankov, B., Klein, M., Njoku, E. G., Bosch, D., Coleman, T. L., Laymon, C. A., and Starks, P.: Polarimetric Scanning Radiometer C- and X-Band Microwave Observations During SMEX03, IEEE T. Geosci. Remote., 43, 2418-2430, 2005.

Kerr, Y. H.: Soil moisture from space: Where are we?, Hydrogeol. J., 15, 117-120, 2007.

Kerr, Y. H., Waldteufel, P., Wigneron, J.-P., Martinuzzi, J.-M., Font, J., and Berger, M.: Soil Moisture Retrieval from Space: The Soil Moisture and Ocean Salinity (SMOS) Mission, IEEE T. Geosci. Remote., 39(8), 1729-1735, 2001.

Kerr, Y. H., Waldteufel, P., Wigneron, J.-P., Martinuzzi, J.-M., Font, J., and Berger, M.: Soil Moisture Retrieval from Space: The Soil Moisture and Ocean Salinity (SMOS) Mission, IEEE T. Geosci. Remote., 39(8), 1729-1735, 2001.

Koster, R., Dirmeyer, P., Guo, Z., Bonan, G., Chan, E., and Cox, P.: Regions of strong coupling between soil moisture and precipitation, Science, 305, 1138-1140, 2004.

Loew, A.: Impact of surface heterogeneity on surface soil moisture retrievals from passive microwave data at the regional scale: the Upper Danube case, Remote Sensing of Environment, 112, 231248, doi:doi:10.1016/j.rse.2007.04.009, 2008.

Loew, A. and Mauser, W.: On the disaggregation of passive microwave soil moisture data using a priori knowledge of temporal persistent soil moisture fields, IEEE T. Geosci. Remote., 46, 819-834, 2008.

Loew, A., Ludwig, R., and Mauser, W.: Derivation of surface soil moisture from ENVISAT ASAR WideSwath and Image mode data in agricultural areas, IEEE T. Geosci. Remote., 44(4), 889899, 2006.

Loew, A., DallAmico, J., Schlenz, F., and Mauser, W.: The Upper Danube soil moisture validation site: measurements and activities, in: Proc. Earth Observation and Water Cycle conference, Frascati (Rome), 18-20 November 2009, ESA-SP-674, 2009a.

Loew, A., Holmes, T., and de Jeu, R.: The European heat wave 2003: early indicators from multisensoral microwave remote sensing?, J. Geophys. Res., 114, D05103, doi:10.1029/2008JD010533, 2009b.

Martinez-Fernnandez, J. and Ceballos, A.: Mean soil moisture estimation using temporal stability analysis, J. Hydrol., 312, 28-38, 2005.

Mauser, W. and Bach, H.: PROMET - Large scale distributed hydrological modelling to study the impact of climate change on the water flows of mountain watersheds, J. Hydrol., 376, 362-377, doi:10.1016/j.jhydrol.2009.07.046, 2009. 
Meesters, A. G. C. A., deJeu, R., and Owe, M.: Analytical Derivation of the Vegetation Optical Depth From the Microwave Polarization Difference Index, IEEE T. Geosci. Remote., 2(2), 121123,2005

Miralles, D., Crow, W., and Cosh, M. H.: Estimating spatial sampling errors in coarse-scale soil moisture estimates derived from point-scale observations, J. Hydrometeorol., in press, doi:10.1175/2010JHM1285.1, 2010.

Njoku, E., Jackson, T., Lakshmi, V., Chan, T., and S. V., Nghiem: Soil moisture retrieval from AMSRE, IEEE T. Geosci. Remote., 41, 215-229, 2003.

Owe, M., de Jeu, R., and Holmes, T.: Multi-Sensor Historical Climatology of Satellite-Derived Global Land Surface Moisture, J. Geophys. Res., 113, F01002, doi:1029/2007JF000769, 2008.

Pauwels, V. R. N., Timmermans, W., and Loew, A.: Comparison of the estimated water and energy budgets of a large winter wheat field during AgriSAR 2006 by multiple sensors and models, J. Hydrol., 349, 425-440, 2008.

Peischl, S., Walker, J., Allahmoradi, M., Barrett, D., Gurney, R., Kerr, Y., Kim, E., LeMarshall, J., Rüdiger, C., D., R., and N., Y.: Towards Validation of SMOS Using Airborne and Ground Data Over the Murrumbidgee Catchment, in: 18th World IMACS Congress and MODSIM09 International Congress on Modelling and Simulation, edited by: Anderssen, R. S., Braddock, R. D., and Newham, L. T. H., Modelling and Simulation Society of Australia and New Zealand and International Association for Mathematics and Computers in Simulation, 3733-3739, 2009.

Philip, J.: The theory of infiltration: 1 . The infiltration equation and its solution, Soil Sciences, 83, 345-357, 1957.

Press, W., Teukolsky, S., Vetterling, W., and Flannery, B.: Numerical recipes in FORTRAN: the art of scientific computing, Cambridge Univ Pr, 1992.

Reichle, R., Koster, R., Dong, J., and Berg, A.: Global Soil Moisture from Satellite Observations, Land Surface Models, and Ground Data: Implications for Data Assimilation, J. Hydrol., 5, 430-442, 2004.

Robock, A., Vinnikov, K. Y., Srinivasan, G., Entin, J. K., Hollinger, S. E., Speranskaya, N. A., Liu, S., and Namkha, A.: The Global Soil Moisture Data Bank, B. Am. Meteorol. Soc., 1281-1299, 2000.

Rüdiger, C., Calvet, J. C., Gruhier, C., Holmes, T., de Jeu, R., and Wagner, W.: An Intercomparison of ERS-Scat, AMSR-E Soil Moisture Observations with Model Simulations over France, J. Hydrol., 10, 431-447, 2009.

Sahr, K., White, D., and Kimerling, A. J.: Geodesic Discrete Global Grid Systems, Cartography and Geographic Information Science, 30, 121-134, 2003.

Saleh, K., Wigneron, J., Waldteufel, P., deRosnay, P., Schwank, M., Calvet, J., and Kerr, Y.: Estimates of surface soil moisture under grass covers using L-band radiometry, Remote Sens. Environ., 109, 42-53, 2007.

Schwank, M., Mätzler, C., Guglielmetti, M., and Flüher, H.: LBand Radiometer Measurements of Soil Water Under Growing Clover Grass, IEEE T. Geosci. Remote., 43, 2225-2237, 2005.
Scipal, K., Holmes, T., deJeu, R., and Wagner, W.: A Possible Solution for the Problem of Estimating the Error Structure of Global Soil Moisture Datasets, Geophys. Res. Lett., 35, L24403, doi:10.1029/2008GL035599, 2009.

Stoffelen, A.: Toward the true near-surface wind speed: Error modeling and calibration using Triple Collocation, J. Geophys. Res., 103, 7755-7766, 1998.

Teuling, A. J., Uijlenhoet, R., Hupet, F., van Loon, E. E., and Troch, P. A.: Estimating spatial mean root-zone soil moisture from point-scale observations, Hydrol. Earth Syst. Sci., 10, 755767, doi:10.5194/hess-10-755-2006, 2006.

Vachaud, G., Passerat de Silans, A., Balabanis, P., and Vauclin, M.: Temporal stability of spatially measured soil water probability density function, Soil Sci. Soc. Am. J., 49, 822-828, 1985.

van de Griend, A., Wigneron, J., and Waldteufel, P.: Consequences of surface heterogeneity for parameter retrieval from $1.4 \mathrm{GHz}$ multiangle SMOS observations, IEEE T. Geosci. Remote., 41, 803-811, 2003.

Vereecken, H., Kamai, T., Harter, T., Kasteel, R., Hopmans, J., and Vanderborght, J.: Explaining soil moisture variability as a function of mean soil moisture: A stochastic unsaturated flow perspective, Geophys. Res. Lett., 34, L22402, doi:10.1029/2007GL031813, 2007.

Vinnikov, K. Y., Robock, A., Speranskaya, N. A., and Schlosser, C. A.: Scale of temporal and spatial variability of midlatitude soil moisture, J. Geophys. Res., 101, 7163-7174, 1996.

Wagner, W., Naeimi, V., Scipal, K., deJeu, R., and MartínezFernández, J.: Soil moisture from operational meteorological satellites, Hydrogeol. J., 15, 121-131, 2007.

Wagner, W., Pathe, C., Doubkova, M., Sabel, D., Bartsch, A., Hasenauer, S., Bloeschl, G., Martinez-Fernandez, J., and Loew, A.: Temporal stability of soil moisture and radar backscatter observed by the Advanced Synthetic Aperture Radar (ASAR), Sensors Journal, 8, 1174-1197, 2008

Walker, J. P. and Houser, P. R.: Requirements of a global nearsurface soil moisture satellite mission: accuracy, repeat time, and spatial resolution, Adv. Water Resour., 27, 785-801, 2004.

Walker, J. P., Willgoose, G. R., and Kalma, J. D.: In situ measurement of soil moisture: a comparison of techniques, J. Hydrol., 293, 85-99, 2004.

Wigneron, J., Calvet, J., de Rosnay, P., Kerr, Y., Waldteufel, P., Saleh, K., Escorihuela, M., and Kruszewski, A.: Soil moisture retrievals from biangular L-band passive microwave observations, IEEE T. Geosci. Remote, 1, 277-281, 2004.

Wigneron, J.-P., Calvet, J.-C., Pellarin, T., Van de Griend, A. A., Berger, M., and Ferrazzoli, P.: Retrieving near-surface soil moisture from microwave radiometric observations: current status and future plans, Remote Sens. Environ., 85, 489-506, 2003.

Yoo, C.: A ground validation problem of remotely sensed soil moisture data, Stochastic Environmental Research And Risk Assessment, 16, 175-187, doi:10.1007/s00477-002-0092-6, 2002.

Zribi, M. and Dechambre, M.: A new empirical model to retrieve soil moisture and roughness from C-band radar data, Remote Sens. Environ., 84, 42-52, 2002. 